\title{
'n Ondersoek na die vokaalduur van die esofagale Afrikaanssprekende
}

\author{
Mariette Botha B(Log)(Pret) \\ Transvalia Skool vir Epileptici, Pretoria
}

\begin{abstract}
OPSOMMING
In hierdie studie is daar 'n ondersoek gedoen na die ooreenkoms wat daar bestaan tussen die vokaalduur van normaalsprekendes en die vokaalduur van esofagale sprekers. Daar is gepoog om die verband tussen spraakvaardigheid en vokaalduur van die esofagroep esofagale sprekers bepaal. Die invloed van die stemhebbendheid/stems postvokaalduur en spraakvaardigheid vain dieselfde duur is ook vasgestel.
\end{abstract}

Dit blyk uit die resultate dat die lengte ten opsigte van die vokaalduur by die groep esofagale sprekers wisselend was, maar in kaalduur en spraakvaardigheid vasstel nie, hoewel daar 'n meer aantoonbare verband tussen vokaaloonbare verband tussen vospraakvaardigheid is. Die duur van die vokale in die stemhebbend-stemlose konsonand tussen vokaal plus postvokaalduur en hoofsaaklik langer as die duur van hierdie vokale in die stemebbend-stemlose konsonantomgewings by die esofagale sprekers was

\section{SUMMARY}

In this study the relationship between the duration of vowels in normal speaking persons and esophageal speakers was investigated. Attempts were made to assess the relationship between the speech capability and vowel duration of esophageal speakers was assessed. The influence of the voiced/vois post vowel duration and speech skill of the same group of esophageal assessed.

From the results it appeared that vowel duration in the esophageal group varied, but in some cases it was similar to that of the normal speaking persons. Investigations could not establish a positively identifiable relationship between vowel duration and duration of vowels in the voiced - voiceless consonant environment was mostly longer vowel duration and speech skill. The voiceless consonant environment as is the case with normal speakers.

Die duur van 'n klank kan omskryf word as die tyd wat dit neem om die klank te artikuleer. ${ }^{5}$ Korrekte vokaalduur is noodsaaklik vir die verstaanbaarheid van die spreker se spraak, omrede dit 'n groot invloed het op die persepsie van linguïstiese eienskappe soos byvoorbeeld die herkenning van foneme. ${ }^{3}$

Die rol wat vokaalduur speel in die verstaanbaarheid van 'n spreker se spraak spreek duidelik uit die volgende feite:

- Die voorafgaande vokaalduur het 'n invloed op die waarneming van die daaropvolgende konsonant as stemhebbend of stemloos. ${ }^{3}$

- Verder kan die betekenis van die totale woord moontlik beinvloed word wanneer die vokaalduur verander, omrede ons in Afrikaans 'n lang en kort uitspraak aantref van dieselfde vokaal, byvoorbeeld [kas/ka:s]

- Vokaalduur en vokaalintensiteitsverhoudings speel albei 'n rol in die beoordeling van aanwesigheid van klem in ' $n$ woord. Vokaalduur is egter 'n meer effektiewe en betroubaarder metode om klem aan te' dui. ${ }^{4}$ As die vokaalduur dan foutief is, sal klempatrone ook foutief voorkom en die woord of lettergreep sal dan foutief perseptueer word.

Dit is dus duidelik dat korrekte vokaalduur 'n belangrike aspek van normale spraakproduksie is. Die esofagale spreker moet leer om sy artikulators op só 'n manier te manipuleer dat hy maksimale benutting van sy beperkte lugvoorraad bekom om beide vokale en konsonante te produseer wat soortgelyk is aan die produksie van die normaalsprekende. ${ }^{8}$

Die doel van hierdie studie is om vokaalduur by die esofagalk Afrikaanssprekende te vergelyk met die vokaalduur van dit natuurlik Afrikaanssprekende persoon en om te bepaal of daar 'n verband is tussen die vaardigheid van die esofagale spreker en korrekte vokaalduur. 


\section{EKSPERIMENTELE METODE}

Die agt eksperimentele proefpersone se ouderdomme het gewissel vanaf 49 jaar tot 71 jaar en die nege kontrole proefpersone is geselekteer om hierdie ouderdomsomvang te pas, $\mathrm{nl}$. met ouderdomme tussen 51 jaar en 68 jaar. Manlike proefpersone is gebruik vir albei groepe. Die totale tydperk van terapie en tydperk sedert operasie is nie konstant gehou in die seleksie van die eksperimentele proefpersone nie, aangesien die enigste vereiste in hierdie opsig was dat die proefpersoon esofagale spraak gebruik vir kommunikasie.

Sprakopnames is gedoen op 'n Nakamitchi bandopnemer nommer 556 en TDK SA90 - kassette is gebruik: Vir die meting van vokaalduur in ms. is ' $n$ Digitale Herhalingslyn Model 2A gebruik.

Elke proefpersoon se gehoor is eers getoets om te bepaal of die persoon voldoen aan die kriteria vir seleksie, nl. gehoor binne normale perke. Tydens die eksperiment het die ondersoeker tesame met die proefpersoon stelling ingeneem in 'n klankdigte eenheid vir spraakopnames. Die ondersoeker het telkens die inleidende $\sin$ en die konsonant-vokaal-konsonantwoorde voorgelees waarna die proefpersoon dit herhaal het. Voor elk van die konsonant-vokaal-konsonantwoorde is daar van die volgende inleidende sin gebruik gemaak, nl. "Ek sê ..." Die volgende

a. [kat, kit, ket, kət, kət]

b. [gat, git, get, gat, got]

c. [pat, pit, pet, pat, pot]

d. [bat, bit, bet, bət, bot]

Slegs kort vokale is gebruik vir die doel van hierdie studie, omdat die produksie van kort vokale hoër eise stel aan die vinnig opeenvolgende sluitings- en openingsfunksie van die neoglottis. Die rede vir seleksie van die genoemde eksplosiewe konsonante is dat hierdie klanke makliker en duideliker waarneembaar is op die Digitale Herhalingslyn en dus kan meting meer akkuraat uitgevoer word.

Om 'n tydsmeting van die betrokke vokaal te maak, is die Digitale Herhalingslyn eerstens ingestel sodat die begin van die vokaal aan die linkerkant van die eerste ossiloskoop se skerm val. Die begin van die, vokaal is geneem waar duidelike ossilasies op die skerm 'n patroon begin vorm het en die einde van die vokaal is geneem waar daar 'n skielike afsluiting van die patroon van ossilasies was. Tydens die bepaling van die duur van die verskillende vokale is daar opgemerk dat daar na die skielike beëindiging van die groot amplitudepatroon vormende ossilasies van die vokale, kleiner amplitude-ossilasies voorgekom het. Die postvokaalduur is geneem vanaf die einde van ossilasial soos reeds beskryf, tot aan die einde van die sigbare nie. Die en nie tot by die begin van die finale konsonant [t] lende uiting van die postvokaalossilasies is vir vier verskilin elke groep [kat, git, put, bet] van elk van die proefpersone Leesstuk opnames is gedoe

esofagale opnames is gedoen om die spraakvaardigheid van die luisteraars is gesele bepaal. 'n Groep van vyf gesofistikeerde puntskaal bestaande is geseleer om die beoordeling te doen. 'n Vyfuitgedeel sodat unde uit ses kategorieë is aan elke luisteraar beoordeling nl:

Die Suid-Afrikaanse Tydskrif vir Kommunikasieafwykings, Vol. 30, 1983 a) Algemene verstaanbaarheid van die persoon se woord en sinsuitinge.

b) Die mate van nie-funksionele steurende stoma- en luginnamegeruise wat voorkom gedurende spraak.

c) Die mate waarin die persoon in staat is om luidheid en toonhoogte effektief aan te wend gedurende spraak, met ander woorde stemgebruik.

d) Die mate van akkuraatheid van die artikulatoriese bewegings.

e) Die mate waarin die spraaktempo (spoed van opeenvolging van lettergrepe) en die kontinuiteit (pouses wat voorkom in die spraakstroom) van die esofagale spreker ooreenstem met dié van die normaalsprekende.

f) Die mate van luisteraangenaamheid in die spreker se stem, met ander woorde stemkwaliteit.

Die totale spraakvaardigheid van elke spreker is soos volg bereken op die vyfpuntskaal: 'n gemiddelde vaardigheidstelling is bereken deur die ses vaardigheidstellings van elk van die vyf luisteraars bymekaar te tel en 'n gemiddeld te bereken vir elke spreker. Die volgende syferwaardes vir kategoriale plasing van proefpersone as meer- en mindervaardig, is arbitrêr gekies nl.:

- die syfer 1-2,5 verteenwoordig die meervaardige sprekers.

- oor die syfer 2,5-3,5 kan geen besliste uitspraak gelewer word nie, aangesien dit deur die beoordelaars as grensge-
valle beoordeel is.

- die syfer 3,5-5 verteenwoordig die mindervaardige sprekers.

Om te bepaal of daar ' $n$ verband bestaan tussen vokaalduur en spraakvaardigheid is daar van 'n $95 \%$ betroubaarheidsinterval gebruik gemaak wat bereken is vir die normaalsprekende groep se vokaalduuruitings.

Vir die bepalings van die invloed van stemhebbendheid en stemloosheid van die konsonantomgewing op die duur van die vokaal, is daar vir die eksperimentele groep sowel as die kontrolegroep van profielontledings gebruik gemaak om sodoende vir elkeen van die twee groepe, die vokaalduur in die stemhebbend-stemlose konsonantomgewing te vergelyk met die vokaalduur in die stemloos-stemlose konsonantomgewing.

\section{RESULTATE}

\section{RESULTATE VAN VOKAALDUURMETINGS:}

Dit het geblyk dat die $[a, c, ~ \jmath]$ in beide die [k-t] en [g-t]- konsonantomgewings met verkorte duur uitgespreek is deur die eksperimentele groep, soos vergelyk met die kontrolegroep. Die $[i, u]$ is met verlengde duur uitgespreek deur die eksperimentele groep in beide die [k-t] en [g-t]-konsonantomgewings. Daar is dus by die esofagale sprekers meer vokale wat met 'n verkorte fonasieduur uitgespreek is, as vokale met ' $n$ verlengde fonasieduur, in vergelyking met die normaalsprekendes. Daar is gevind dat die $[u]$ in beide die $[p-t]$ en [b-t]-konsonantomgewings deur die groep eksperimentele sprekers verleng is en die [a] in beide die genoemde konsonantomgewings deur die groep eksperimentele sprekers verkort is.

\section{RESULTATE VAN SPRAAKVAARDIGHEIDSBEOORDELINGS:}

Die resultate toon dat daar vyf van die agt esofagale sprekers is wat as meervaardig beoordeel is en slegs een spreker is wat as mindervaardig beoordeel is. Daar kan geen besliste 

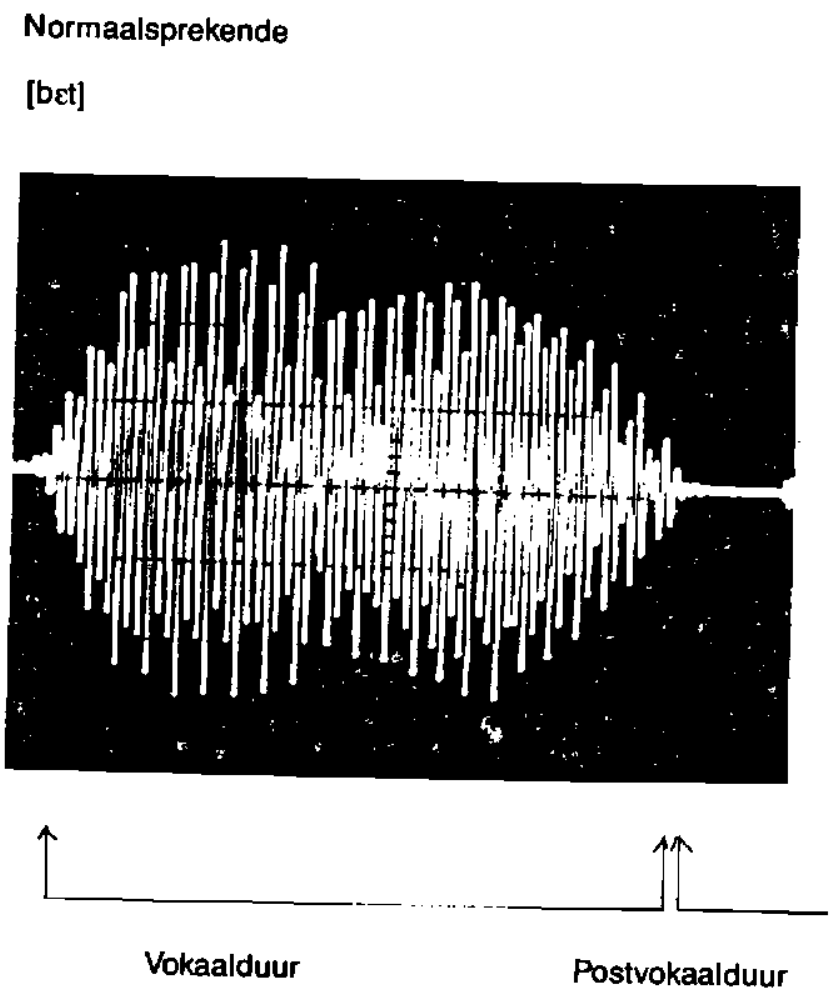

Esofagale spreker

[bet]
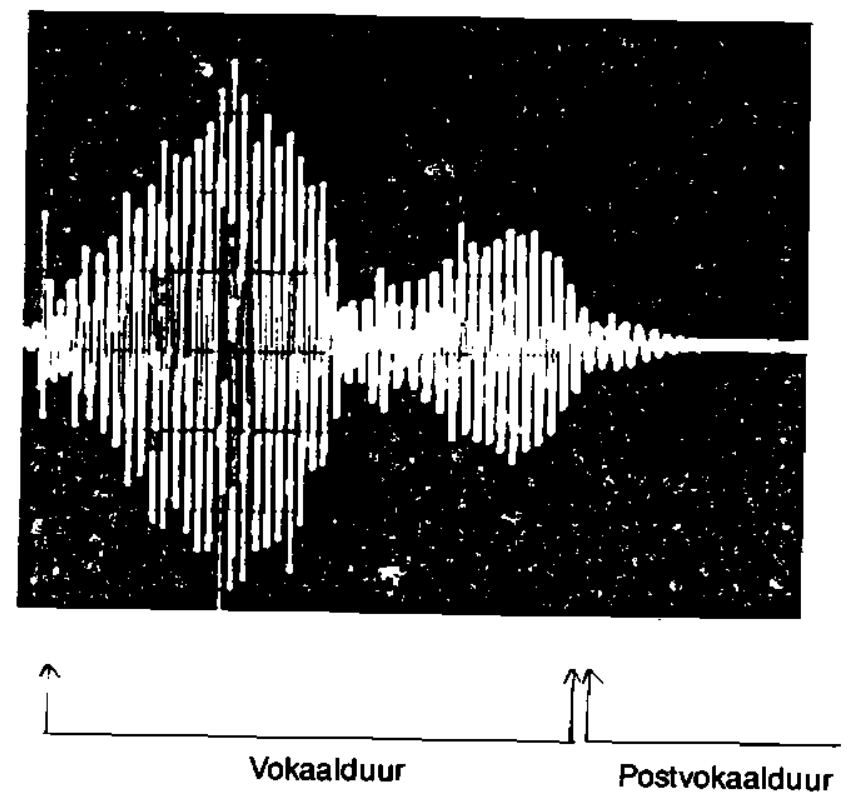

Normaalsprekende

[kat]
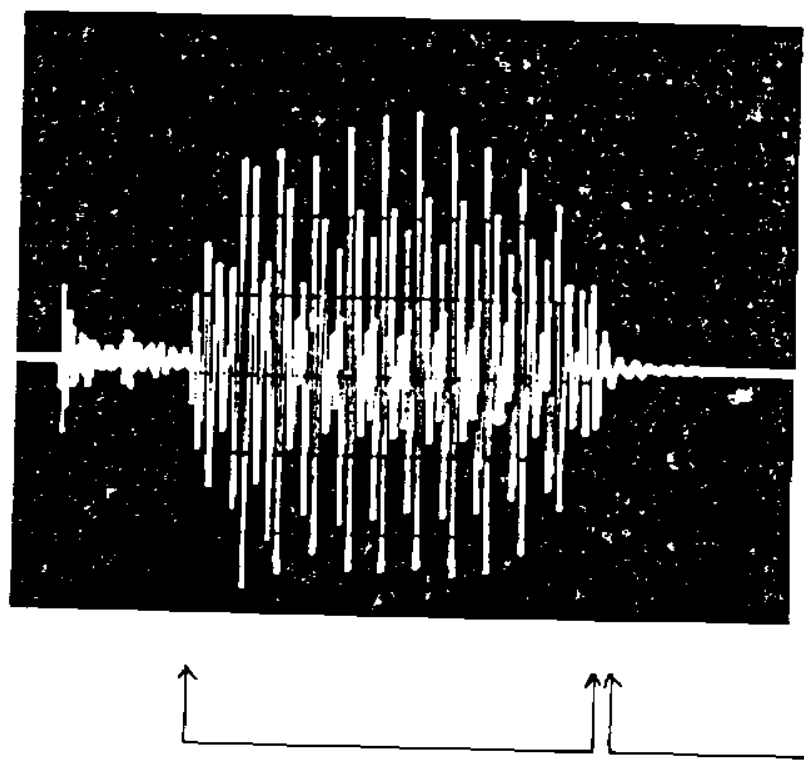

Vokaalduur

Postvokaalduur

Esofagale spreker

[kət]
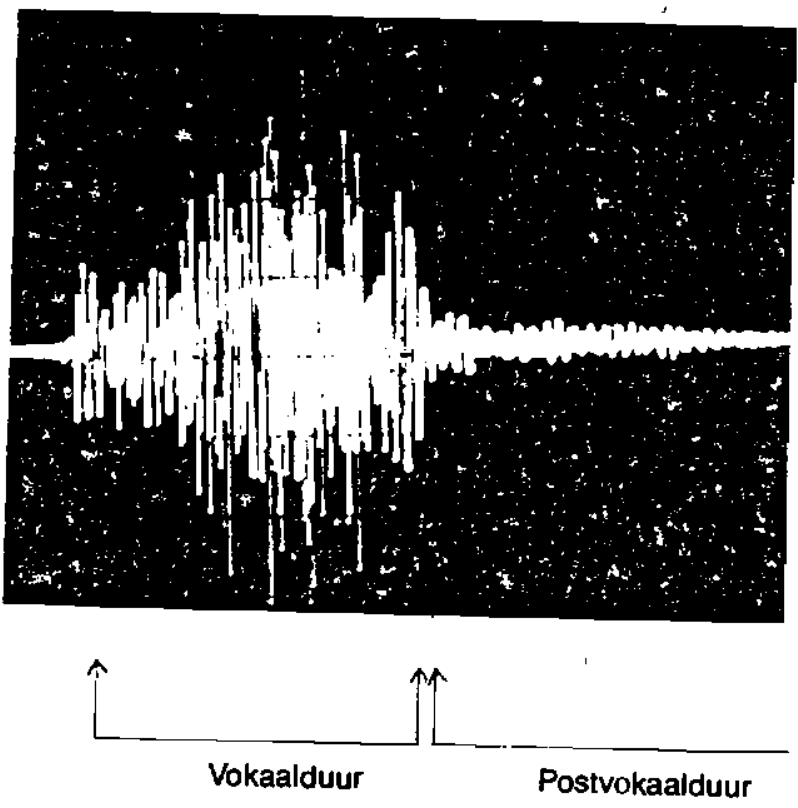

Figuur 1 Vokaal- en postvokaalduur in stemlose en stemhebbende konsonant omgewings van normaal en esofagale sprekers 
uitspraak gelewer word oor die vaardigheid van twee van die sprekers nie, as gevolg van gevarieerde tellings tussen meeren mindervaardig. Hulle vaardigheidstellings word dan as grenstellings beskou.

\section{RESULTATE VAN DIE VERBAND TUSSEN SPRAAKVAARDIGHEID} EN VOKAALDUUR VAN DIE ESOFAGALE SPREKERS:

Daar is ses van die agt esofagale sprekers met gemiddelde vokaalduurtellings wat binne die intervalomvangs val soos daargestel deur die normaalsprekendes. Daar is dus slegs twee esofagale sprekers met afwykende vokaalduurtellings wat buite die intervalomvangs val soos daargestel deur die normaalsprekendes. Hierdie esofagale sprekers is deur die luisteraars beoordeel as meervaardig. Hulle vokaalduurtellings was korter as die tellings wat deur die interval gegee word. By die twee esofagale sprekers waar daar geen besliste uitspraak gelewer kon word oor hulle vaardigheid nie, is daar gevind dat hulle vokaalduurtellings binne die intervalomvangs val.

DIE INVLOED VAN STEMHEBBEND- EN STEMLOOSHEID VAN DIE KONSONANTOMGEWING OP VOKAALDUUR:

Al die vokale, [a, $\varepsilon, i, \jmath, \partial, u]$, het 'n verlengde vokaalduur getoon in die stemhebbend-stemlose konsonantomgewing [bt] in vergelyking met die stemloos-stemlose konsonantomgewing [p-t] by die normaalsprekende. Daar blyk 'n eweredige vokaalduurverlenging te wees vir al die vokale, wanneer die stemhebbend-stemlose konsonantomgewing beskou word teenoor die stemloos-stemlose konsonantomgewing. By die esofagale sprekers het daar nie sulke eweredige vokaalduurverskille voorgekom soos by die normaalsprekendes nie. Daar het by die normaalsprekendes telkens slegs verlenging van die vokaalduur voorgekom in die stemhebbend-stemlose konsonantomgewings in vergelyking met die stemloos-stemlose konsonantomgewings, maar by die esofagale sprekers was daar verlengings en verkortings van vokaalduur in die stemhebbendstemlose konsonantomgewings. Daar was groter vokaalduurverskille opmerklik by die normaalsprekendes wanneer die stemhebbend-stemlose konsonantomgewings vergelyk is met die stemloos-stemlose konsonantomgewings, byvoorbeeld by die normaalsprekendes was daar 'n verlenging van die vokaalduur in 'n stemhebbend-stemlose omgewing van $11 \mathrm{~ms}$ vir die woord [bot] teenoor die esofagale sprekers waar daar vir dieselfde woord slegs:'n verlenging van $1 \mathrm{~ms}$ was.
Uit die resultate kom dit voor dat die esofagale sprekers net soos die normaalsprekendes die vokaal verleng het wanneer die vokaal voorgekom het in 'n stemhebbend-stemlose konsonantomgewing. Die esofagale sprekers vertoon egter 'n mindere mate van verlenging van die vokaal in 'n stemhebbendstemlose konsonantomgewing. Daar word dus 'n duideliker onderskeid gemaak tussen stemhebbendheid en stemloosheid van die konsonantomgewing soos gesien in vokaalduurmetings, by die normaalsprekende, as by die esofagale spreker.

\section{RESULTATE VAN POSTVOKAALDUURMETINGS:}

Tydens die meting van die vokaalduur plus postvokaalduur van die esofagale sprekers, sowel as die normaalsprekendes is daar gevind dat die postvokaalduur baie langer was vir die eksperimentele groep, as vir die normaalsprekende groep vir al vier die konsonant-vokaal-konsonant-verbindings. (Verwys na Tabel I.)

Wanneer die eksperimentele groep se vokaal plus postvokaalduur vergelyk word met die kontrolegroep se vokaal plus postvokaalduur is daar ' $n$ duidelike verskil in vokaalduur te sien. Die eksperimentele groep se vokaal plus postvokaalduur is baie langer as die kontrolegroep se vokaal plus postvokaalduur.

RESULTATE VAN VOKA'AL PLUS POSTVOKAALDUURMETINGS SOOS IN VERBAND GEBRING MET BETROUBAARHEIDSINTERVALSOMVANG:

Wanneer postvokaalduur saam met vokaalduur in ag geneem word, is daar meer esofagale sprekers (vyf uit agt) met 'n afwykende vokaalduur (langer as normaalsprekendes) in vergelyking met vokaalduur sonder postvokaalduur waar net twee uit agt esofagale sprekers afwykende vokaalduur (korter as normaalsprekendes) aantoon.

\section{BESPREKING VAN RESULTATE}

Die gemiddelde vokaalduur vir die groep esofagale sprekers het in só 'n mate gevarieer dat geen deurlopende patroon opgemerk kon word nie. Daar is gevind dat die vokaalduur by die groep esofagale sprekers wisselend (korter of langer) was, maar in gevalle het dit ook ooreengestem met die normaalsprekendes.

Geen algemene afleiding kan gemaak word ten opsigte van die verskille in vokaalduur tussen die groepe esofagale sprekers en

Tabel 1 Gemiddelde vokaalduurtellings en postvokaalduurtellings vir beide die eksperimentele groepe en kontrolegroepe

\begin{tabular}{|c|c|c|c|c|}
\hline $\begin{array}{l}\text { *Proefpersone } \\
\text { (E) en }(\mathbf{K})\end{array}$ & KVK-verbinding & $\begin{array}{l}\text { Vokaalduur } \\
\text { alleen }\end{array}$ & $\begin{array}{l}\text { Postvokaalduur } \\
\text { alleen }\end{array}$ & $\begin{array}{l}\text { Vokaal plus } \\
\text { postvokaalduur }\end{array}$ \\
\hline $\begin{array}{l}K \\
E\end{array}$ & [kət] & $\begin{array}{l}71 \mathrm{~ms} \\
78 \mathrm{~ms}\end{array}$ & $\begin{array}{l}18 \mathrm{~ms} \\
44 \mathrm{~ms}\end{array}$ & $\begin{array}{r}89 \mathrm{~ms} \\
122 \mathrm{~ms}\end{array}$ \\
\hline $\begin{array}{l}\mathbf{K} \\
\mathbf{E}\end{array}$ & [git] & $\begin{array}{l}96 \mathrm{~ms} \\
93 \mathrm{~ms}\end{array}$ & $\begin{array}{l}18 \mathrm{~ms} \\
43 \mathrm{~ms}\end{array}$ & $\begin{array}{l}114 \mathrm{~ms} \\
136 \mathrm{~ms}\end{array}$ \\
\hline $\begin{array}{l}K \\
E\end{array}$ & [put] & $\begin{array}{l}79 \mathrm{~ms} \\
83 \mathrm{~ms}\end{array}$ & $\begin{array}{l}11 \mathrm{~ms} \\
49 \mathrm{~ms}\end{array}$ & $\begin{array}{r}91 \mathrm{~ms} \\
132 \mathrm{~ms}\end{array}$ \\
\hline $\begin{array}{l}\mathrm{K} \\
\mathrm{E}\end{array}$ & [bet] & $\begin{array}{l}124 \mathrm{~ms} \\
114 \mathrm{~ms}\end{array}$ & $\begin{array}{l}14 \mathrm{~ms} \\
28 \mathrm{~ms}\end{array}$ & $\begin{array}{l}138 \mathrm{~ms} \\
147 \mathrm{~ms}\end{array}$ \\
\hline
\end{tabular}

$\mathrm{E}=$ Eksperimentele groep
$\mathrm{K}=\mathrm{K}$ Kontrolegroep

Kontrolegroep

Die Suid-Afrikaanse Tydskrif vir Kommunikasieafwykings, Vol. 30,1983 
normaalsprekendes nie., Wanneer daar egter gekyk word na afsonderlike vokaalduurtellings by die verskillende individue, is dit duidelik dat sommige van die esofagale sprekers soms afwykende vokaalduurpatrone vertoon. Die vraag ontstaan dus nou of individuele afwykende vokaalduurpatrone, - soos wat wel voorkom, maar net verskuil is in die groepsresultate - by die esofagale spreker 'n invloed het op die verstaanbaarheid van die spreker se uitings.

Swisher ${ }^{8}$ het 'n studie gedoen met esofagale Engelssprekendes, waarin hy gevind het dat die duur van die vokale verleng word deur die esofagale sprekers. Hy vind 'n verdubbeling van vokaalduur by sommige van die vokale, soos uitgespreek deur 'n esofagale spreker in vergelyking met 'n normaalsprekende. Christensen en Weinberg' het 'n soortgelyke studie gedoen en soortgelyke resultate gevind. Kritiek teen Swisher ${ }^{8}$ se metode van vokaalduurmeting is dat hy nie nét die vokaal gemeet het toe hy die "friction period" bygemeet het, en die vokaal geneem het tot waar die finale konsonant begin nie. Dit is belangrik om te onthou dat ' $n$ vokaal duidelike formante moet hê om as vokaal gedefinieer te word.?

Tydens die meting van die vokaalduur is daar wel opgemerk dat daar aan die einde van die vokaal (soos op die ossiloskoop gesien) nog opsigtelike, postvokaal klein amplitudeossilasies, voorkom by al die esofagale sprekers en soms ook by die normaalsprekendes. 'n Moontlike verklaring vir hierdie verskynsel is dat die aanvang en afsluiting van stemgewing vinnig en doeltreffend beheer kan word deur die beweging van die stemlippe by die normaalsprekende, maar by die esofagale spreker is dit moontlik dat die beweging van die pseudoglottis tydens die sametrekking en ontspanning van die sfinkterspier, nie vinnig en ferm genoeg kan plaasvind nie, wat dan resulteer in voortgaande vibrasiesiklusse (verwys na Figuur 1). Die onvoldoende werking van die neuromuskulêre meganisme veroorsaak dat 'n "geluid" steeds sal voorkom na die produksie van die vokaal. Hierdie "geluid" kan nie as deel van die vokaal beskou word nie, as gevolg van geen duidelike patroonvormende ossilasies nie.

Die vraag wat vooraf in hierdie bespreking ontstaan het oor die moontlike invloed van afwykende vokaalduurpatrone op die verstaanbaarheid van die esofagale spreker se uitings kan moontlik nou beantwoord word. Tydens die beoordeling van die esofagale sprekers se spraakvaardigheid op die vyfpuntskaal vir die ses verskillende parameters, was een van die parameters die beoordeling van algemene verstaanbaarheid van woord en sinsuitinge. Daar is gevind dat die duur van die vokaal nie 'n oorwegende rol speel in die verstaanbaarheid van esofagale spraak nie. Dit kan toegeskryf word aan die resultaat dat die esofagale sprekers wat afwykende vokaalduur getoon het nogtans deur die luisteraars as baie goed verstaanbaar beoordeel is. Die een spreker wat as baie moeilik verstaanbaar beoordeel is, het 'n gemiddelde vokaalduur getoon wat binne die normale intervalomvangs geplaas is. Binder' maak die opmerking dat die akoestiese faktore wat saamval met verhoogde verstaanbaarheidsbeoordelings blyk verbind te wees aan verhoogde pseudoglottiese beheer oor esofagale lugvrylating. Die afleiding kan dus gemaak word dat daar baie ander faktore is wat die algemene verstaanbaarheid van esofagale spraak beïnvloed byvoorbeeld steurende stoma- en luginnamegeruise, swak artikulasie, asook algemene afwykende spraaktempo en kontinuïteitspatrone.
Tydens die ondersoek na die invloed van afwykende vokaalduur op spraakvaardigheid is daar in groepsverband nie ' $n$ 'op. sigtelike verband tussen vokaalduur en spraakvaardigheid gevind nie. Daar is egter 'n duideliker verband gevind tussen vokaal plus postvokaalduur en spraakvaardigheid. Goeie beheer van vokaalduur kan dus wél 'n bydrae lewer tot goeie spraakvaardigheid.

Tydens die bepaling van die invloed van stemhebbendheid en stemloosheid van die konsonantomgewing op die duur van die vokaal, is daar gevind dat by die normaalsprekendes, die vokaalduur langer was waar die vokaal voorafgegaan is deur ' stemhebbende konsonant en gevolg is deur 'n stemlose konsonant, as waar die inisiële en finale konsonante albei stemloos was in die konsonant-vokaal-konsonant-kombinasie. By die esofagale sprekers was die vokaalduur egter gevarieerd langer en korter gewees waar die vokaal in 'n stemhebbend-stemlose konsonantomgewing geplaas is, en dan vergelyk word met die vokaal in 'n stemloos-stemlose konsonantomgewing. Die gemiddelde verlenging van die vokaalduur was baie minder by die esofagale sprekers as by die normaalsprekendes. Hier is dus nie duidelike stemhebbend/stemlose onderskeid by die "sofagale spreker nie. Binder' haal Nichol aan, naamlik, "Voicing is a vulnerable feature in esophageal speech intelligibility".

Twee moontlike verklarings vir die toename in vokaalduur in die stemhebbend-stemlose konsonantomgewing kan soos volg gegee word, naamlik:

- Dat verlenging van hierdie vokaal moontlik die rede is waarom die stemlose konsonant wat voorafgegaan word deur die vokaal dan deur die oor as stemhebbend perseptueer word. Weismer, Dinnsen en Elbert ${ }^{9}$ het in Engels gevind dat die vokaalduur langer was waar die vokaal 'n stemhebbende konsonant voorafgegaan het.

- Wanneer die inisiële konsonant wat geproduseer word stemloos is, verkeer die pseudoglottis in 'n ontspanne toestand. Moolenaar-Bijl' sê dat as die stemlose konsonant direk opgevolg word deur 'n vokaal, dan word die ingepersde esofagale lug gebruik vir die produksie van die vokaal. Die Kriko-faringale spier trek saam sodat daar vernouing plaasvind van die pseudoglottis en die vokaal dan geproduseer kan word. Indien die finale daaropvolgende konsonant dan weer stemhebbend is, is die pseudoglottis alreeds in 'n geaddukeerde toestand sodat dit maklik is om die stemhebbende konsonant te produseer, máár as dịe finale opvolgende konsonant stemloos is, dan moet daar vinnige ontspanning van die sfinkterspier plaasvind. Dit is dus 'n vinnig opeenvolgende "openings-sluitings-openings"-aksie wat meer bewegingsvaardigheid van die pseudoglottis verg.

Die inligting wat uit die resultate verkry is, is nie genoegsaam om veralgemenings te maak ten opsigte van die rol van korrekte vokaalduur in esofagale spraak nie, maar die vokaalduur "abnormaliteite" wat wel by sommige van die individuele esofagale sprekers voorgekom het, blyk 'n invloed te hê op spraakvaardigheidsbeoordelings en verstaanbaarheid. Dit is duidelik dat esofagale spraak nie nét deur vokaalduurafwykings beïnvloed word nie, maar ook deur ander faktore soos steurende stoma- en luginnamegeruise asook afwykende latente periodes. 


\section{GEVOLGTREKKINGS}

Die gevolgtrekkings wat uit hierdie ondersoek gemaak kan word, is die volgende:

- Dat daar esofagale sprekers is wat soms afwykende vokaalduur vertoon in hulle spraak. Die gemiddelde vokaalduur vir die esofagale groep sprekers het in so 'n mate gevarieer dat geen deurlopende patroon opgemerk kon word nie, omdat die esofagale sprekers gevarieerd langer of korter, of soms dieselfde vokaalduur getoon het as die normaalsprekendes.

- Dat daar nie 'n opsigtelike verband bestaan tussen vokaalduur en spraakvaardigheid nie, omdat die luisteraars se beoordelings van die meer- en mindervaardige sprekers nie ooreenstem met die spreker se normale- of abnormale vokaalduurtellings nie. Daar is 'n duideliker verband tussen vokaal plus postvokaalduur en spraakvaardigheid omrede die luisteraars die meeste van die esofagale sprekers met normale vokaalduur ook geklassifiseer het as meervaardige sprekers, en die esofagale spreker met abnormale vokaalduur geklassifiseer het as mindervaardig.

- Die esofagale sprekers probleme ondervind om effektiewe stemhebbend/stemlose onderskeid te tref van die konsonantomgewing waarin die vokaal voorkom. Die mate van onderskeid tussen die stemhebbendheid en stemloosheid van die konsonantomgewing is baie duideliker by die normaalsprekende.

Uit die resultate wat in hierdie studie verkry is, sien ons dus dat die esofagale spreker 'n groot hoeveelheid van motorieskomplekse aspekte van spraak het om aan te leer, om sodoende as 'n vaardige en verstaanbare spreker beskou te kan word.

\section{BEDANKINGS}

My dank aan die volgende persone: Mev. A. van der Merwe en mnr. H. E. C. Tesner, Kolonel L. P. C. Jansen van die For. Wet. Laboratorium vir die gebruik van apparaat.

\section{VERWYSINGS}

1. Binder, G. (1978): Selected Acoustic Characteristics of Emerging Esophageal Speech: Case Study. The South African Journal of Communication Disorders, Vol. 25, pp. 24-51.

2. Christensen, J. M. en Weinberg, B. (1976): Vowel Duration Characteristics of Esophageal Speech. Journal of Speech and Hearing Research. Vol. 19, pp. 678-689).

3. Denes, P. (1955): Effect of Duration on the Perception of Voicing. Journal of the Acoustical Society of America, Vol. 27, no. 4, pp. 761-764).

4. Fry, D. B. (1955): Duration and Intensity as Physical Correlates of Linguistic Stress. Journal of the Acoustical Society of America, Vol. 27, no. 4, pp. 765-768).

5. Le Roux, T. H. en Pienaar, P. de V. (1927): Afrikaanse Fonetiek. Johannesburg, Juta en Kie Bpk.

6. Moolenaar-Bijl, A. (1953): Connection between Consonant Articulation and the Intake of Air in Esophageal Speech. Folia Phoniatrica, Vol. 5, pp. 212-215).

7. Potter, R. K., Kopp, G. A. en Green, H. C. (1947): Visible Speech. D. van Nostrand Company, Inc., New York.

8. Swisher, W E. (1980): Oral Pressures, Vowel Durations and Acceptability Ratings of Esophageal Speakers. Journal of Communication Disorders, Vol. 13, pp. 171-181.

9. Weismer, G., Dinnsen, D. A. en Elbert, M. (1979): A Clinical Study of the Voicing Distinction and Final Stop Deletion. Indiana University Linguistics Club, Lindley Hall, Indiana. 